\title{
Orientation-specific color effects without adaptation
}

\author{
GORDON STANLEY and WILLIAM C. HOFFMAN \\ University of Melbourne, Parkville, Victoria 3052, Australia
}

Twelve observers naive in relation to McCollough-type phenomena reported subjective colors when viewing a figure consisting of four wedges of dark bars on white, each wedge being oriented at 90 deg to each other wedge. A desaturated reddish-pink was reported for the vertical wedge and a desaturated green-blue for the horizontal wedge. These effects occurred without prior adaptation to color and were orientation specific.

McCollough (1965) reported a color aftereffect dependent on the orientation (vertical or horizontal) of straight line gratings. After exposure to vertical black lines on an orange background alternated with horizontal black lines on a blue background, a desaturated blue-green was seen on the background of a test grating of vertical lines and an orange on the background of a horizontal test grating. Such color effects would alternate if the subject's head turned through $90 \mathrm{deg}$ and were not visible at an orientation of $45 \mathrm{deg}$. Since the original report of McCollough, numerous parameters of the effect have been studied, it being found that chromatic aftereffects can be made contingent on a variety of spatial patterns (Skowbo, Timney, Gentry \& Morant, 1975).

One of the most surprising aspects of the phenomenon has been the persistence of the effect. Stromeyer and Mansfield (1970) reported an aftereffect as long as 6 weeks after a 20-min adaptation to moving gratings. Other workers have noted that this long persistence creates some difficulties for an adaptation account of the effect and have proposed an association learning account (Jones \& Holding, 1975; Skowbo et al., 1975).

The present communication reports some evidence to support a serendipitous observation that orientationspecific color effects can occur without adaptation. When Figure 1 is observed under the conditions reported below, shimmering blue and green bands are seen that suddenly turn into solid wedges of pastel green and pink in alternate sectors of the figure. These subjective colors are orientation specific and alternate when the head is turned through $90 \mathrm{deg}$.

\section{METHOD}

Subjects

The subjects were 12 naive observers who had never been subjects in a McCollough-type adaptation experiment.

\section{Apparatus}

Figure 1 was presented by means of a Kodak Carousel pro-

William C. Hoffman is a Visiting Fellow. Permanent address: Department of Mathematical Science, Oakland University, Rochester, Michigan 48063. jector onto a standard white projection screen. The visual angle subtended by the spaces between the dark lines was $30 \mathrm{~min}$, the subjects being seated at a distance of $174 \mathrm{~cm}$ from the screen. Pattern luminance as measured by an SEI photometer was 5.57 lumen/meter. A control slide of straight vertical bars on a white background was also made.

\section{Procedure}

Subjects were tested individually, first viewing the slide of vertical bars and being asked to report any appearance of pastel color associated with the slide. The purpose of this slide was to enable us to eliminate any subjects with a guessing bias. (Sufficient observers in our laboratory have observed the effect without the prior presentation of the control slide to insure that it has no function in producing the colors observed with Figure 1.) Next the subjects were presented with Figure 1 and again asked to report any color associated with the slide. They were then asked to turn their heads through 90 deg and to report any impression of color and, finally, to turn their heads to an angle of $45 \mathrm{deg}$ with respect to the screen and to report any color.

\section{RESULTS AND DISCUSSION}

All 12 observers reported subjective colors, the most common response being reddish or pink for the vertical wedge and pale green for the horizontal wedge. Two subjects only reported seeing pink in the vertical wedge. All found the impression of color to switch segments when their heads turned through $90 \mathrm{deg}$. No color or

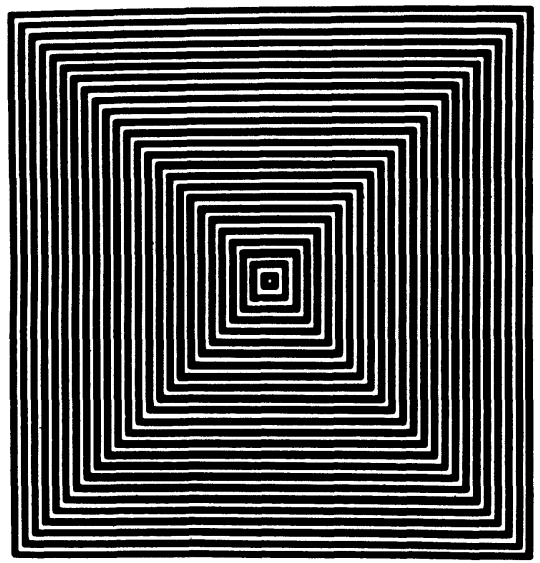

Figure 1. Orientation-specific subjective colors are perceived in the wedges of this figure when viewed under the conditions described in the text. 
desaturated uniform color across the whole pattern was seen at $45 \mathrm{deg}$.

A further subject, a male with red-green color defect, perceived brown rather than the pastel blue-green and red reported by normal viewers.

In their comprehensive survey of subjective color phenomena, Cohen and Gordon (1949) noted only two patterns, devised by Luckiesh and Moss and Skinner, respectively, that gave rise to subjective color without some sort of motion in the stimulus pattern, such as a rotating Benham disk. The Luckiesh-Moss pattern, like that of Figure 1, induces pastel shades transverse to the lines of the pattern. The subjective color phenomena evoked by such stationary black-and-white patterns are unlike the McCollough effect in that the latter requires prolonged illumination by light of a definite color (orange or blue) to establish the necessary adaptation. On the other hand, once this adaptation has been established, it apparently predisposes toward the perception of subjective color in the stationary black-and-white pattern case.

Some subjects, while viewing Figure 1, reported a dark shadow rotating in an approximately circular pattern about the center of symmetry. This resembles certain aspects of MacKay's (1961) complementary afterimages (CAI) and suggests an investigation to determine whether the black-and-white pattern used to evoke CAI might also evoke subjective color. That such color illusions as reported here frequently occur in black-andwhite patterns appears to be well known among practitioners of optical art (Perola, 1969, p. 113, p. 117), where they are often attributed to Moire effects; indeed, Figures $3-8,3-21,3-29,4-45,4-54,4-55$, and $5-1$ of that reference do induce subjective colors just às well as the present Figure 1. Many of these patterns are recogniz- able as orbits of the constancies (Hoffman, 1966a, b), as is also true for the McCollough effect and related studies (Held \& Shattuck, 1971; Riggs, 1973). Others, like Bridget Riley's "Current" (Perola, 1969, Figure 5-1) appear to result from a tendency on the part of the visual system to force the subjective color patterns into the constancy orbit closest to that transverse to the perceived figural element.

\section{REFERENCES}

Coren, J. A. \& Gordon, D. A. The Prevost-Fechner-Benham subjective colors. Psychological Bulletin, 1949, 46, 97-136.

Held, R., \& Shatruck, S. R. Color- and edge-sensitive channels in the human visual system: Tuning for orientation. Science, 1971, 174, 314-316.

Hoffman, W. C. The lie algebra of visual perception. Journal of Mathematical Psychology, 1966, 3, 65-98. (a)

Hoffman, W. C. Comments on optical art. Applied Optics, $1966,5,873-874$. (b)

Jones, P. D., \& Holding, D. H. Extremely long-term persistence of the McCollough effect. Journal of Experimental Psychology: Human Perception and Performance, 1975, 1, 323-327.

MACKAY, D. M. Interactive processes in visual perception. In W. A. Rosenblith (Ed.), Sensory communication. Cambridge, Mass: M.I.T. Press, 1961. Pp. 339-355.

McCollougr,' C. Color adaptation of edge-detectors in the human visual system. Science, 1965, 149, 1115-1116.

Perola, R. Optical art. New York: Beekman House, 1969.

Riggs, L. A. Curvature as a feature of pattern vision. Science, 1973, 181, 1070-1072.

Skowbo, D., Timney, B. N., Gentry, T. A. \& Morant, R. B. McCollough effects: Experimental findings and theoretical accounts. Psychological Bulletin, 1975, 82, 497-510.

(Received for publication February 19, 1976.) 